\title{
O desenvolvimento de um e-book para identificar fake news: o bibliotecário como mediador na criação de critérios de avaliação da informação
}

Bruna Heller, FURG, brunahellerbh@gmail.com

Joice Rejane Pardo Maurell, FURG, joicerejane@ @urg.br

Resumo: O artigo descreve o projeto de ação de um curso de especialização EAD lato sensu em TIC, da Universidade Aberta do Brasil - UAB. Foi realizado em uma escola particular em Estância Velha-RS. Teve por objetivo desenvolver um e-book com critérios de avaliação para checagem de informação, visando um trabalho em conjunto de uma bibliotecária com alunos de $1^{\circ}$ ano do Ensino Médio. A tecnologia digital escolhida foi o livro digital, elaborado na ferramenta Canva. Seguindo a metodologia educativa Ensino por Projetos, o projeto de ação foi de caráter qualitativo e descritivo, com aplicação de questionários. Após a realização das atividades, analisou-se questionários, além de considerar relatos, e observou-se apropriação em relação à tecnologia digital, à ferramenta e à importância de checar a informação antes de disseminá-la. Assim, teve-se uma ação interdisciplinar, proporcionando aos alunos o conhecimento de uma tecnologia digital antes desconhecida, além da noção de um olhar mais crítico para a informação.

Palavras-chave: tecnologias de informação e comunicação (TIC); ciência da informação; desinformação; Canva; Ensino por Projetos.

\section{Developing an ebook to identify fake news: the librarian as a mediator in the creation of information evaluation criteria}

Abstract: The article describes the action project of a lato sensu distance education specialization course at the Universidade Aberta do Brasil - UAB. The project was held at a private school in Estância Velha-RS. The objective was to develop an e-book with evaluation criteria for disinformation checking, aiming at a joint work of a librarian with first year high school students. The digital technology chosen was the digital book, mounted on the Canva tool. Following the educational methodology Teaching by Projects, the action project methodology was qualitative and descriptive, with the application of questionnaires. After performing the activities, questionnaires were analyzed, as well as considering reports, and there was appropriation regarding digital technology, the tool and the importance of checking information before disseminating it. Thus, there was an interdisciplinary action, providing students with knowledge of a previously unknown digital technology, in addition to the notion of a more critical look at information.

Keywords: information and communication technology (ICT); information Science; disinformation; Canva; Teaching by Projects.

\section{Introdução}

O presente artigo relata a experiência de um projeto de ação, bem como a sua análise qualitativa, evidenciando a atividade proposta em um curso de especialização lato sensu em Tecnologias de Informação e Comunicação (TIC), ofertado pela Universidade Aberta do Brasil - UAB, na modalidade EAD.

$\mathrm{Na}$ era digital, vive-se a cultura da desinformação. A palavra, que significa "Informação inverídica ou errada que é divulgada com o objetivo de induzir em erro" segundo o dicionário Aurélio (Ferreira, 2010, p. 688), vai ao encontro da pós-verdade 
(D’Ancona, 2018). Pós-verdade foi eleita como palavra do ano ${ }^{1}$ em 2016 pelo Oxford Dictionaries, definida como "circunstâncias em que os fatos objetivos são menos influentes em formar a opinião pública do que os apelos à emoção e à crença pessoal" (BBC, 2016, n. p., tradução nossa). Berckemeyer (2017, n. p.) diz que "O componente emocional, por outro lado, tampouco é nada novo: para 'reforçar preconceitos' poucas coisas foram mais eficientes e praticadas que manipular emoções", considerando um ponto chave de motivação dos sujeitos para compartilhamento e uso da informação.

Ou seja, a disseminação da informação cada vez mais se dá pelo simples ato de compartilhar sem a necessidade de que a fonte seja verificada, importando na maioria das vezes a afinidade de quem está compartilhando com a informação encaminhada. Uma das consequências são as chamadas fake news ${ }^{2}$.

A fidedignidade das fontes de cada postagem é questionável, uma vez que o volume de informações não possibilita aos indivíduos considerar fontes confiáveis tudo aquilo que é publicado. Assim, a área da ciência da informação tem o papel fundamental de atuar enquanto mediadora, sendo o bibliotecário o sujeito que age recuperando, analisando e disponibilizando informações para cada necessidade informacional. Mas além disso, o mesmo tem o papel de capacitar informacionalmente os seus usuários.

Assim, o projeto de ação teve por objetivo desenvolver um e-book com critérios de avaliação para a informação, visando um trabalho em conjunto de uma profissional bibliotecária com os alunos de uma turma de $1^{\circ}$ ano do Ensino Médio.

As atividades emergiram da importância de utilizar nos espaços de aprendizagem as ferramentas digitais, que instiguem o fazer do aluno, além da vontade de desenvolver o senso crítico frente à informação. Para o e-book, foi utilizado o site $\mathrm{Canva}^{3}$. O projeto de ação buscou responder: como o bibliotecário pode mediar a criação de um livro digital e a apropriação quanto aos critérios de avaliação de informação com alunos de $1^{\circ}$ ano do Ensino Médio?

A metodologia educativa foi Ensino por Projetos, uma vez que buscou investigar uma temática que instigasse os alunos a apresentar soluções frente a um problema. O presente artigo apresenta o relato de experiência, das ações desenvolvidas no projeto de ação, assumindo uma metodologia de enfoque qualitativo e descritivo.

Esperou-se que com esta pesquisa os alunos tivessem, a partir de uma experiência interdisciplinar, a noção de um olhar mais crítico para a informação, além de desenvolver habilidades para criarem $e$-books e seus próprios conteúdos digitais.

\section{A potencialidade do $e$-Book}

O $e$-Book ou livro digital, do inglês book que significa livro e $e$ que é uma denominação para itens digitais, trata-se de um recurso tecnológico com a mesma função de um livro físico: disseminar informação. Simbolizando um upgrade da leitura, como sugere Furtado e Santos (2017), o livro digital desprendeu uma nova concepção, que exige do leitor um dispositivo para a leitura, que muitas vezes interage consigo, facilitando a sua vida. Com os avanços tecnológicos digitais, a ferramenta possibilitou diversas facilidades inovadoras, como acesso simultâneo, de custo reduzido, com maior interação e que, no quesito pedagógico, instiga e aproxima-se da realidade digital dos alunos, considerados nativos digitais (Prensky, 2001).

\footnotetext{
${ }^{1}$ Pós-verdade é tradução nossa para o termo em inglês post-truth.

${ }^{2}$ Do inglês "notícias falsas". O significado aproxima-se do conceito de misinformation, que significa informação errada, mas pode aproximar-se do conceito de disinformation, que significa informação errada com intencionalidade de induzir ao erro. Fake news é considerada um tipo de desinformação. ${ }^{3}$ Disponível em: https://www.canva.com/. Acesso em: 08 set. 2019. DOI: 
Pensando nas potencialidades de um livro digital, pode-se destacar vantagens no quesito técnico: as opções de acessibilidade que oferece ao leitor (aumento de fonte de letra, possibilidade de mudança na luminosidade, algumas plataformas disponibilizam a versão falada etc), ferramentas de pesquisa dentro do próprio conteúdo do livro, hiperlinks, entre outros. Sem mencionar a questão socioambiental, que ao produzir menor quantidade de papel contribui-se para a preservação do meio ambiente.

Atinente, o uso de tecnologias digitais desperta curiosidade, estimulando a aprendizagem, através de uma atenção que o professor consegue captar por meio dessas ferramentas digitais. Hoje, são recursos fundamentais para um bom planejamento do ensino. Furtado e Santos (2017) dizem que o uso de $e$-Books como TIC é "entreter a criança despertando sua curiosidade, injetando na prática da leitura as informações necessárias e específicas a cada faixa etária para que a criança avance criticamente seu nível intelectual" (Furtado; Santos, 2017, p. 50).

Assim, desenvolver habilidades que induzam ao uso dessa ferramenta digital é enriquecedor para o aluno e uma provocação para o mediador/professor, uma vez que no contexto de bibliotecas é possível trabalhar o incentivo à leitura através de ferramentas que os alunos são familiarizados e instiga o profissional a sair da sua zona de conforto e capacitar-se para ofertar melhores possibilidades aos educandos.

Arruda (2009, p. 18) diz que "houve uma dinamização no processo de produção, acesso e compreensão do conhecimento" com a explosão da internet, pois os usuários de informação que são consumidores são os próprios produtores de conteúdo, e gerenciar esse volume de informações apresenta grandes desafios de uma pesquisa.

Ainda, Arruda (2009) entende o educador como um mediador no espaço de ensino, mas salienta que

considera-se que essa realidade apresentada à escola com a inserção das novas tecnologias não representa apenas outra postura do profissional da educação perante o conhecimento desenvolvido com seus alunos, representa profunda ruptura com as formas anteriores de ensino/aprendizagem (Arruda, 2009, p. 20).

Entende-se que não basta mesclar métodos digitais com as práticas tradicionais, mas sim adaptar-se à educação contemporânea. Esse processo ocorre quando o docente assume o papel de mediador, promovendo uma quebra de paradigmas, que desafiam o educador a dominar ferramentas e estratégias para que a realidade digital seja compreendida e aplicada nas mediações entre aluno e conhecimento.

\section{A desinformação e as fake news}

A sociedade produz, consome e dissemina informação, principalmente de forma virtual por meio da web, a todo instante. Capurro (2009) define esta sociedade como sociedade da informação, que caracteriza-se por criar e utilizar a todo momento novas TIC, e que resulta em um novo conjunto de questões e de princípios nos ambientes sociais, ou seja, reconfigura-se nas relações sociais e pessoais.

Serra (2014) menciona que os usuários de informação de hoje são na maioria a geração Y, que "são consideradas dessa geração as crianças nascidas no início dos anos 1980 até 1990 " (Serra, 2014, p. 17) e que estas enfrentam um conflito no momento de decisão sobre uma fonte de informação (Serra, 2014). O acesso com a era digital possibilitou uma maior propagação, e a viabilidade de alteração nos conteúdos, o que é reconhecido por desinformação e que ameaça a credibilidade dos fatos.

Segundo Ferreira (2010, p. 688), desinformação é a “informação propositadamente desvirtuada, deformada ou falseada para induzir o adversário em erro V. $17 \mathrm{~N}^{\circ}$ 3, dezembro, 2019 RENOTE DOI: 
de apreciação". O termo popular e que está muito em voga, principalmente após a disseminação de desinformação na época das eleições norte-americanas de 2016, é fake news, que é um dos tipos de desinformação.

As fake news são uma crise das atualizações da informação, que emerge o caos informacional dentro do contexto em que se está a informação (Leite; Matos, 2017). Assim, cria-se um ambiente perigoso em virtude de diversas questões das partes que a propagam: econômicas (muitos utilizam a disseminação da desinformação como forma de geração de renda), políticas (em guerras, por exemplo, diversas desinformações são espalhadas a fim de atrasar o adversário), disputa de poder (em eleições políticas).

A não-chegada da informação pode significar alienação. Leite e Matos (2017) dizem "a internet possibilitou maximizar a comunicação. As redes sociais fizeram emergir a disseminação da criatividade comunicativa humana. [...] Todos querem deixar seu legado memético" (Leite; Matos, 2017, p. 2342). Os mais impactados são as pessoas de menor instrução (Frias Filho, 2018).

Ademais, a pós-verdade, termo que dá sentido à era em que preocupa-se mais com que as histórias pareçam reais e tenha repercussão do que sejam - de fato - fatos (D'Ancona, 2018), traz à tona o caos informacional e a possível zumbificação da sociedade (Leite; Matos, 2017). Desde o Iluminismo, que vislumbrou disseminar o conhecimento científico, "vem sendo formada sob influência do método científico e do racionalismo moderno, o que tende a resultar numa atitude mais criteriosa em face das informações disponíveis" (Frias Filho, 2018, p. 42), mas como menciona o autor não trata-se de uma maioria da população que está nessa camada.

Mesmo com a intenção de erradicar a desinformação, não existe uma fórmula específica que acabe com as fake news, mas sim habilidades que podem ser desenvolvidas a fim de impactar os problemas que rodeiam o ciberespaço. É preciso encontrar espaços de luta por democratização da informação, pois a cada momento o inverídico dá espaço a formação de opiniões errôneas e extremistas, conforme diz Frias Filho (2018).

A profissão de bibliotecário, regulamentada desde 1964 no Brasil, evoluiu ao longo dos anos, passando de guardador de livros para disseminador de informação, conforme propõe Santos (2012). É atualmente o profissional que tem competências informacionais para atender ao seu principal objetivo: auxiliar na busca por informações e, por isso, deve preocupar-se com a disseminação das fontes fidedignas e confiáveis. Fazer a correta e mais precisa gestão informacional é um dos seus desafios.

\section{Metodologias}

\subsection{Metodologia educativa Ensino por Projetos por meio de e-Books}

Buscou-se com o projeto de ação desenvolver a metodologia educativa Ensino por Projetos, que teve como tema a elaboração de e-books e a criação de critérios para checagem de fake news, com a utilização da ferramenta digital Canva. Pereira, Cunha e Oliveira (2014) salientam a importância desta metodologia quando nos fala que

Os projetos escolares, ao serem trabalhados, permitem um envolvimento entre os novos conhecimentos e as práticas cotidianas, dessa forma articulamse as experiências realizadas nos projetos com o contexto vivido pelos alunos. [...] $\mathrm{O}$ ensino não pode estar voltado a contextos distantes da realidade do aluno, mas partir de temas geradores, os quais agirão como ponto de partida na construção do conhecimento (Pereira; Cunha; Oliveira, 2014, p. 180). 
Assim, fomentou-se a investigação por uma questão polêmica, que é como checar se uma informação é fidedigna ou falsa. Para tal, utilizou-se os critérios para avaliação da informação na internet da autora Tomaél (2008), além do teste CRAAP desenvolvido por bibliotecários da Universidade do Estado da California (Meriam, 2019). Outro instrumento utilizado pela pesquisadora para nortear a composição do conteúdo para os alunos foram os critérios definidos pela IFLA (2019). Além desses, os critérios elencados pela pesquisadora Maria Pinto (2018) para avaliar a qualidade dos conteúdos eletrônicos foram considerados.

A turma foi dividida em grupos para que pudessem discutir sobre como podem ser validadas essas informações, a partir de técnicas apresentadas, com materiais utilizados nas aulas. Logo, ao serem protagonistas da ação, desenvolveram a criação de e-books com critérios para validar as fontes de informação.

A ferramenta digital escolhida, Canva, é uma plataforma que "consiste numa das ferramentas de criação de conteúdos gráficos mais simples de utilizar, entre as existentes!" (Lacerda, 2016, n. p.), pois trata-se de uma ferramenta com modelos de designs editáveis, de fácil manuseio, diferente de outros programas de edição de layouts gráficos como Photoshop e CorelDRAW.

Lacerda (2016) atenta para um recurso de aprendizagem: a possibilidade de criar equipes de até 30 usuários colaborando juntos. $\mathrm{O}$ educador pode explorar muitos vieses digitais, funcionando como rede social. Uma aplicabilidade vista pela pesquisadora foi a possibilidade de criar e-books, uma vez a ferramenta desfruta de diferentes dimensões de página. Ao ser trabalhado o $e$-book, foi escolhida a opção "Documento A4", que aproxima-se do tamanho de uma folha de leitura digital.

\subsection{Metodologia de pesquisa}

O projeto foi desenvolvido em uma escola particular localizada na cidade de Estância Velha - RS, em dois meses, com 18 alunos de $1^{\circ}$ ano do Ensino Médio, média de 14 anos. As atividades foram realizadas no laboratório de informática da escola, que disponibilizava 15 computadores com acesso à internet. O objetivo do projeto foi elaborar um livro digital com critérios de avaliação para checagem de fake news. Foram cedidos alguns momentos para que executassem as ações.

O planejamento das ações ocorreu durante alguns meses em 2018 e a execução do projeto foi realizada nos meses de março e abril 2019. Para alcançar os objetivos propostos, o projeto de ação teve abordagem qualitativa, que segundo Prodanov e Freitas (2013, p. 70) é "um vínculo indissociável entre o mundo objetivo e a subjetividade do sujeito que não pode ser traduzido em números".

Quanto à finalidade, optou-se pela pesquisa descritiva, em que "os fatos são observados, registrados, analisados, classificados e interpretados, sem que o pesquisador interfira sobre eles" (PRODANOV; FREITAS, 2013, p. 52). A escolha por essa metodologia foi designada a partir da necessidade de executar um projeto de ação, com sujeitos protagonistas, aprendendo a partir de suas próprias trocas significativas. $\mathrm{O}$ artigo em questão trata-se de um relato de experiência do projeto desenvolvido.

Em relação ao levantamento de informações, foram utilizados os seguintes instrumentos para coleta de dados: questionários - no início e no fim da atividade, diário de bordo, relatórios de atividades, observação e seminários com a turma. A escolha pelo questionário prévio e final deu-se com o intuito de medir os conhecimentos prévios assim como os finais, a partir da experiência realizada. 
A análise foi baseada em Minayo (2012), na qual são elencados aspectos visando a perspectiva qualitativa, em que salienta que o pesquisador deve olhar para a "experiência, vivência, senso comum e ação" dos sujeitos (MINAYO, 2012, p. 622).

\section{A experiência realizada}

No primeiro encontro, teve-se um momento de apresentações e aplicação de um questionário. Já nessa etapa, foi possível avaliar o que os alunos sabiam em relação aos temas trabalhados e se já conheciam as ferramentas. Apesar de um tema atual, nem todos tinham a clareza do tipo de desinformação fake news.

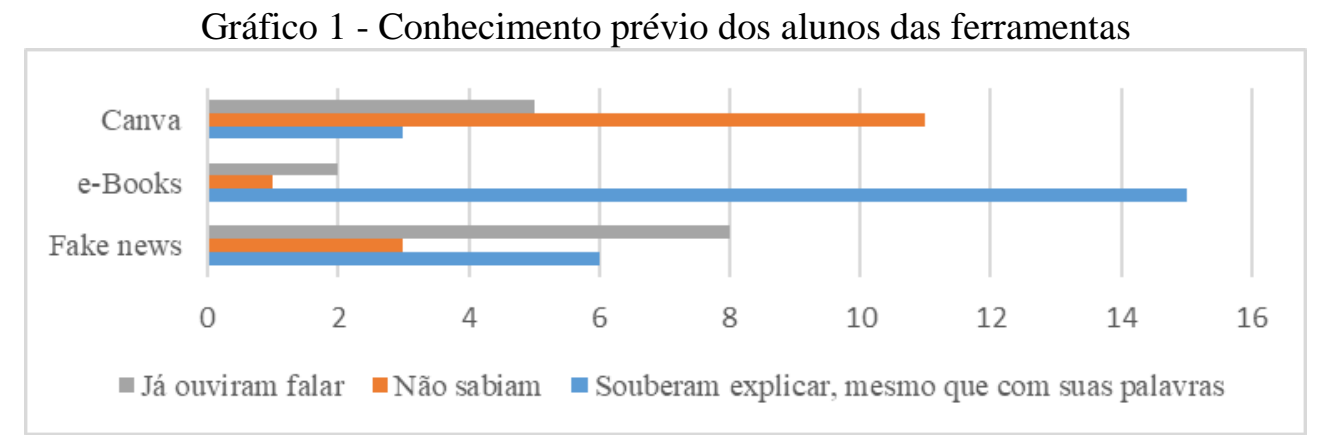

Fonte: dados do projeto.

Com uma apresentação de slides, foi contextualizado o que é a desinformação e as fake news, como avaliar informação na internet e, também, foram mostrados alguns critérios de avaliação de fontes de informação ${ }^{4}$ (Tomaél, 2008; Ifla, 2019; Pinto, 2018; Meriam, 2019). Este foi o fio condutor, ou seja, o tema problematizador que Pereira, Cunha e Oliveira (2014) destacam ser importante para a construção de um projeto.

Os estudantes foram questionados sobre seus procedimentos de pesquisas, quando um professor pedia um trabalho. As respostas foram variadas e muitos desconheciam o conceito de fonte confiável de informação (Tomaél, 2008). Ficou evidenciado que a maioria utilizava fontes como Wikipedia ${ }^{5}$.

Gráfico 2 - Fontes digitais utilizadas pelos alunos para pesquisas escolares.

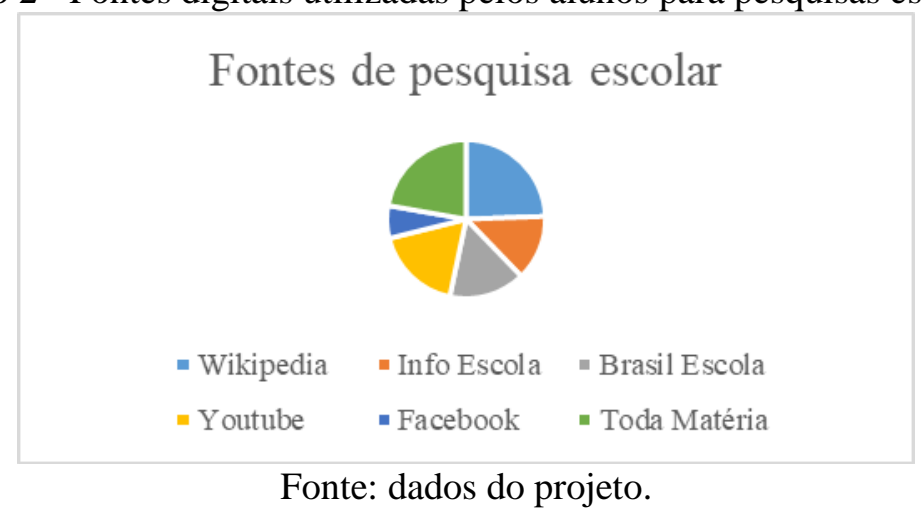

Fonte: dados do projeto.

A parte prática do projeto foi realizada no laboratório de informática, na qual foi feita uma oficina no computador para elaborar livros digitais. Usou-se a ferramenta

4 Os critérios que contribuíram para a composição do conteúdo elaborado pela pesquisadora do projeto estão descritos na seção 4.1 deste artigo.

${ }^{5}$ Wikipedia é uma enciclopédia colaborativa online, com o propósito de "fornecer um conteúdo livre, objetivo e verificável, que todos possam editar e melhorar" (WIKIPEDIA, 2019, n. p.).

V. $17 \mathrm{~N}^{\mathrm{o}}$ 3, dezembro, 2019 RENOTE DOI: 
Canva. Alguns problemas ocorreram, mas a mediação explorou a ferramenta em sua totalidade. Foram trazidos exemplos de livros formatados no Canva.

$\mathrm{Na}$ escola, há o privilégio de se ter estrutura para fazer atividades digitais com um bom laboratório de informática, mas também há o incentivo da gestão escolar aos professores para que essa atividade seja desenvolvida. Essa postura da escola evidenciase também nas respostas nos questionários, conforme Quadro 1. Apesar de usarem internet, o celular não é permitido em sala de aula.

Quadro 1 - Comentários dos alunos quanto ao uso de tecnologias digitais.

Você utiliza tecnologias digitais em sala de aula? Se sim, quais?

\begin{tabular}{|l|l|}
\hline $\begin{array}{l}\text { Aluno } \\
\text { A }\end{array}$ & $\begin{array}{l}\text { "Sim, os professores sempre nos levam até o laboratório pelo menos uma vez } \\
\text { por semana para fazermos alguma atividade. Internet, Word, Powerpoint". }\end{array}$ \\
\hline $\begin{array}{l}\text { Aluno } \\
\text { B }\end{array}$ & "Sim, utilizamos internet, o powerpoint para fazer apresentaços". \\
\hline $\begin{array}{l}\text { Aluno } \\
\text { C }\end{array}$ & $\begin{array}{l}\text { "Os professores sempre nos trazem no laboratório para fazer pesquisas na } \\
\text { internet e outras atividades". }\end{array}$ \\
\hline $\begin{array}{l}\text { Aluno } \\
\text { D }\end{array}$ & $\begin{array}{l}\text { "Uso. Algumas aulas mais do que as outras, em algumas fazemos pesquisas } \\
\text { para trabalhos, outras vemos vídeos". }\end{array}$ \\
\hline $\begin{array}{l}\text { Aluno } \\
\text { E }\end{array}$ & "Sim. Tivemos uma oficina de elaborar aplicativos no celular. Sempre nos \\
\hline
\end{tabular}

Fonte: dados do projeto.

No momento seguinte, foi feita uma atividade prática também no laboratório de informática em que eles iniciaram a confecção das páginas do livro digital. Cada um dos dezoito alunos elaborou uma página. Quem não terminou pôde enviar por e-mail. Para não repetir os temas, antes de iniciarem a prática, dividiu-se alguns critérios. Alguns repetiram-se por não se ter 18 exclusivos.

No encontro posterior e final, foi feita uma rápida apresentação de como ficou o livro digital. Foram recebidos feedbacks de todos, de que a atividade foi muito produtiva porque apresentou conceitos que eles não conheciam, que puderam entender melhor a importância de saber identificar as informações confiáveis, que isso serviria para o futuro deles e de forma agregadora comentaram positivamente sobre o Canva. Mostrou uma certa criticidade por parte dos alunos, pois se posicionaram frente à atividade, conforme mencionado por Pereira, Cunha e Oliveira (2014, p. 176) "é essa criticidade e autonomia que tanto buscamos para que a sociedade se desenvolva e gradativamente se estabeleça em seu processo humanitário".

Figura 2 - Exemplo de páginas confeccionadas por alguns alunos.

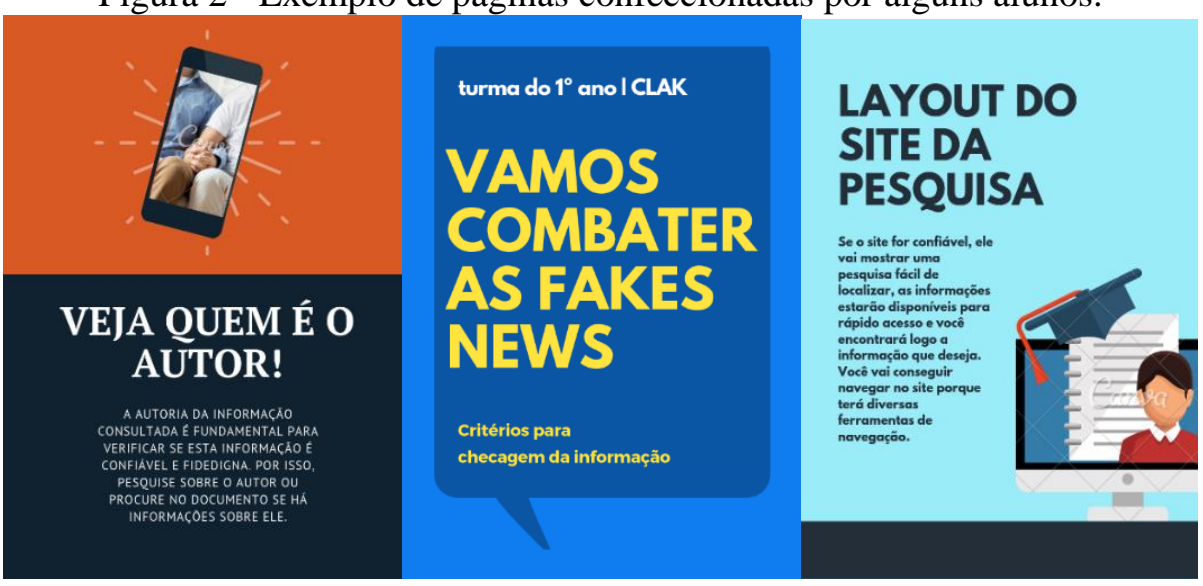

Fonte: dados da pesquisa.

V. $17 \mathrm{~N}^{\circ}$ 3, dezembro, 2019

RENOTE DOI: 
Em relação à ferramenta Canva, ao serem questionados ao final da atividade, a maioria - que não conhecia a ferramenta - gostou muito pela facilidade. Quem já conhecia, surpreendeu-se porque não tinha a noção de que poderia ser utilizada para um fim acadêmico/intelectual, de uma maneira tão fácil e prática, também gratuita.

A produção do e-book totalizou 23 páginas: capa (1), folha de rosto (1), apresentação (1), sumário (1), conteúdo produzido pelos alunos (18), página final (1). Na confecção do livro digital, os alunos tiveram bastante criatividade para pesquisar layouts na ferramenta Canva que ornassem com o assunto que gostariam de desenvolver a página. Alguns escolheram páginas já prontas, outros fizeram uma página compondo com elementos e definindo cores próprias. Os demais escolheram um layout pronto, mas modificaram-no, trocando as suas cores ou acrescentando/deletando elementos.

Em relação à apropriação ao tema fake news e a importância de saber avaliar uma informação, no questionário prévio pôde-se perceber uma divisão de opiniões entre os alunos, o que mudou no questionário final, momento em que posicionaram-se positivamente em relação à aprendizagem pós-atividade. Ao serem questionados sobre um critério de avaliação que utilizariam para avaliar uma informação, todos os 18 alunos responderam com algum dos critérios estudados no projeto.

Esse resultado vai ao encontro das palavras de Frias Filho (2018), que salienta que o mais eficiente combate às fake news ainda é a educação básica de qualidade, que conforme mencionado pelo autor está "apta a estimular o discernimento na escolha das leituras e um saudável ceticismo na forma de absorvê-las" (Frias Filho, 2018, p. 44).

Após esse relato, percebe-se que o objetivo do projeto de ação, que visava a elaboração de um livro digital com critérios para checagem de fake news, foi alcançado, oportunizando novas experiências digitais e informacionais para os alunos, com uma avaliação positiva dos mesmos em relação às atividades exercidas.

\section{Conclusão}

Ao concluir a presente escrita, avalia-se que muitos estudantes que participaram do projeto não tinham ideia de que é fake news, entendendo-o como um conceito muito mais amplo que a identificação de notícias falsas. Ademais, as respostas dos questionários evidenciaram que, por se tratar de um assunto em voga, todos abarcaram e ficaram curiosos sobre como se procederia a atividade. Percebeu-se, também, o envolvimento e comprometimento de toda a turma durante todo o processo.

No contexto informacional, a desinformação sempre foi uma realidade presente. A principal motivação da pesquisadora - enquanto profissional da informação - foi democratizar a informação desenvolvendo competências informacionais nesses sujeitos, ou seja, acreditar na utopia de que a informação será fornecida a todos de maneira igual, claramente e sem a dúvida de ser ou não verdade, e que saibam avalia-la de maneira crítica. Com as redes sociais e a grande massa de produção informacional, seja científica ou não, é um desafio e tanto para os profissionais da informação julgarem a veracidade e confiabilidade desses conteúdos. É emergente que os profissionais da informação entendam essa como um atributo de sua profissão: avaliar as fontes de informação e intermediar o processo com relação aos seus usuários.

Atrelada à proposta do curso, o projeto mesclou a necessidade informacional do usuário, a democratização da informação e o uso de TIC na aprendizagem, visto que foram trabalhados conteúdos digitais de informação. A ideia de avaliar as fontes de informação criando critérios para tal é uma forma de empoderar o aluno e consequentemente toda a sua comunidade a atuarem enquanto cidadãos em busca de 
menor alienação na sociedade. Tendo conhecimentos para disseminar informações através de ferramentas digitais como o Canva, o aluno encontra mais possibilidades no seu processo de aprendizagem.

Houve a preocupação de desassociar todos os tipos de desinformação do termo fake news, sendo explicado em diferentes momentos que as notícias falsas engajaram um movimento de disseminação de desinformações, mas que é preciso pensar mais amplamente porque a desinformação está presente em qualquer contexto informacional e não somente nas informações midiáticas.

Enquanto mediadoras desta ação e pesquisadoras, houve uma satisfação imensa em atuar enquanto profissionais da informação e contribuir para a formação intelectual e sociocultural dessa turma no âmbito digital, assim como apresentar um novo recurso tecnológico como ferramenta educativa, fomentando diversos aspectos como incentivo à leitura, criatividade, escrita, habilidades digitais, entre outros.

\section{REFERÊNCIAS}

ARRUDA, E. Relações entre tecnologias digitais e educação: perspectivas para a compreensão da aprendizagem escolar contemporânea. In: FREITAS, M. T. de A. (Org.). Cibercultura e formação de professores. Belo Horizonte: Autêntica, 2009.

BBC News. 'Post-truth' declared word of the year by Oxford Dictionaries. 2016. Disponível em: https://www.bbc.com/news/uk-37995600. Acesso em: 31 ago. 2019.

BERCKEMEYER, F. A mentira da pós-verdade. 2017. Disponível em: https://www.revista-uno.com.br/numero-27/a-mentira-da-pos-verdade/. Acesso em: 31 ago. 2019.

CANVA. 2019. Disponível em: https://www.canva.com/. Acesso em: 31 ago. 2019.

CAPURRO, R. Ética intercultural de la información. In: GOMES, H. F.; BOTTENTUIT, A. M.; OLIVEIRA, M. O. E. de (Orgs.). A ética na sociedade, na área da informação e da atuação profissional: o olhar da filosofia, da sociologia, da ciência da informação e do exercício profissional do bibliotecário no Brasil. Brasília: CFB. 2009. p. 43-64. Disponível em:

http://repositorio.cfb.org.br/bitstream/123456789/432/1/A\%20\%C3\%89tica\%20na\%20 Sociedade, $\% 20$ na $\% 20 \%$ C3\%81 rea $\% 20 \mathrm{da} \% 20$ Informa $\%$ C3\%A7\%C3\%A3o\%20e\%20d a\%20Atua\%C3\%A7\%C3\%A3o\%20Profissional.pdf. Acesso em: 28 nov. 2018. D’ANCONA, M. Pós-verdade: a nova guerra contra os fatos em tempos de fake news. Barueri: Faro Editorial, 2018.

FERREIRA, A. B. de H. Dicionário Aurélio da língua portuguesa. 5. ed. Curitiba, PR: Positivo, c2010.

FRIAS FILHO, O. O que é falso sobre as fake news. Revista USP, São Paulo, v. 116, p. 39-44, jan. 2018. Disponível em: https://www.revistas.usp.br/revusp/article/vi ew/146576/140222. Acesso em: 10 abr. 2019.

FURTADO, C. C.; SANTOS, D. C. P. dos. Livros digitais interativos como ferramenta lúdica e educacional: incrementos para a leitura da literatura infantil. RICS, Belo Horizonte, v. 3, n. esp., jul./dez. 2017. Disponível em: 
http://www.periodicoseletronicos.ufma.br/index.php/ricultsociedade/article/view/77 43/4795. Acesso em: 17 abr. 2019.

IFLA. How to spot fake news. 2019. Disponível em: https://www.ifla.org/node/11174. Acesso em: 07 dez. 2019.

LACERDA, P. S. Canva: O que é e como utilizar. 2016. Disponível em:

http://blog.cleverweb.com.br/canva-o-que-e-e-como-utilizar/. Acesso em: 31 ago. 2019.

LEITE, L. R. T.; MATOS, J. C. Zumbificação da informação: a desinformação e o caos informacional. In: Congresso Brasileiro de Biblioteconomia e Documentação, 26., 2017, Fortaleza. Anais... Fortaleza: FEBAB, 2017. Disponível em:

https://portal.febab.org.br/anais/article/view/1961/1962. Acesso em: 25 abr. 2019.

MERIAM Library. The CRAAP Test. 2019. Disponível em:

https://library.csuchico.edu/help/source-or-information-goodI. Acesso em: $07 \mathrm{dez}$. 2019.

MINAYO, M. C. S. Análise qualitativa: teoria, passos e fidedignidade. Ciência e saúde coletiva, v. 17, n. 3, p. 621-626, 2012. Disponível em:

http://www.scielo.br/pdf/csc/v17n3/v17n3a07.pdf. Acesso em: 14 dez. 2019.

PEREIRA, K. M. C.; CUNHA, R. M. R. da; OLIVEIRA, E. F. de. O ensino por meio de projetos. Revista Ciências Humanas, Taubaté, v. 7, n. 1, 2014. Disponível em: https://www.rchunitau.com .br/index.php/rch/article/download/127/79. Acesso em: 16 set. 2019.

PINTO, M. calidad y evaluación de los contenidos electrónicos. 2018. Disponível em: http://www.mariapinto.es/e-coms/calidad-y-evaluacion-de-los-contenidos-electronicos/. Acesso em: 07 dez. 2019.

PRENSKY, M. Nativos digitais, imigrantes digitais. On the Horizon, v. 9, n. 5, 2001. Disponível em:

http://www.colegiongeracao.com.br/novageracao/2_intencoes/nativos.pdf. Acesso em 31 ago. 2019.

SANTOS, J. M. O processo histórico evolutivo das bibliotecas da antiguidade ao renascimento. RBBD, São Paulo, v. 8, n. 2, p. 175-189, jul./dez. 2012. Disponível em: https://rbbd.febab.org.br/rbbd/article/view/237/235. Acesso em: 01 dez. 2018.

SERRA, L. G. Livro digital e bibliotecas. Rio de Janeiro: FGV, 2009.

TOMAEL, M. I. Fontes de informação na internet. Londrina: EdUEL, 2008.

WIKIPEDIA. [San Francisco, CA: Wikimedia Foundation, 2010]. Disponível em: https://pt.wikipedia.org/wiki/Wikip\%C3\%A9dia:P\%C3\%A1gina_principal. Acesso em: 12 out. 2019. 